\title{
Humanização e Controle Social: O Psicólogo como Ouvidor Hospitalar
}

\author{
Humanization and social control: \\ The psychologist as \\ health ombudsman
}

Humanización y control social: El psicólogo como oyente de hospital

Denis Barros de Carvalho, Universidade Federal do Piauí

Janaína Macêdo Santana Universidade Estadual do Piauí

Vera Macêdo de Santana Instituto de Doenças Tropicais Natan Portella

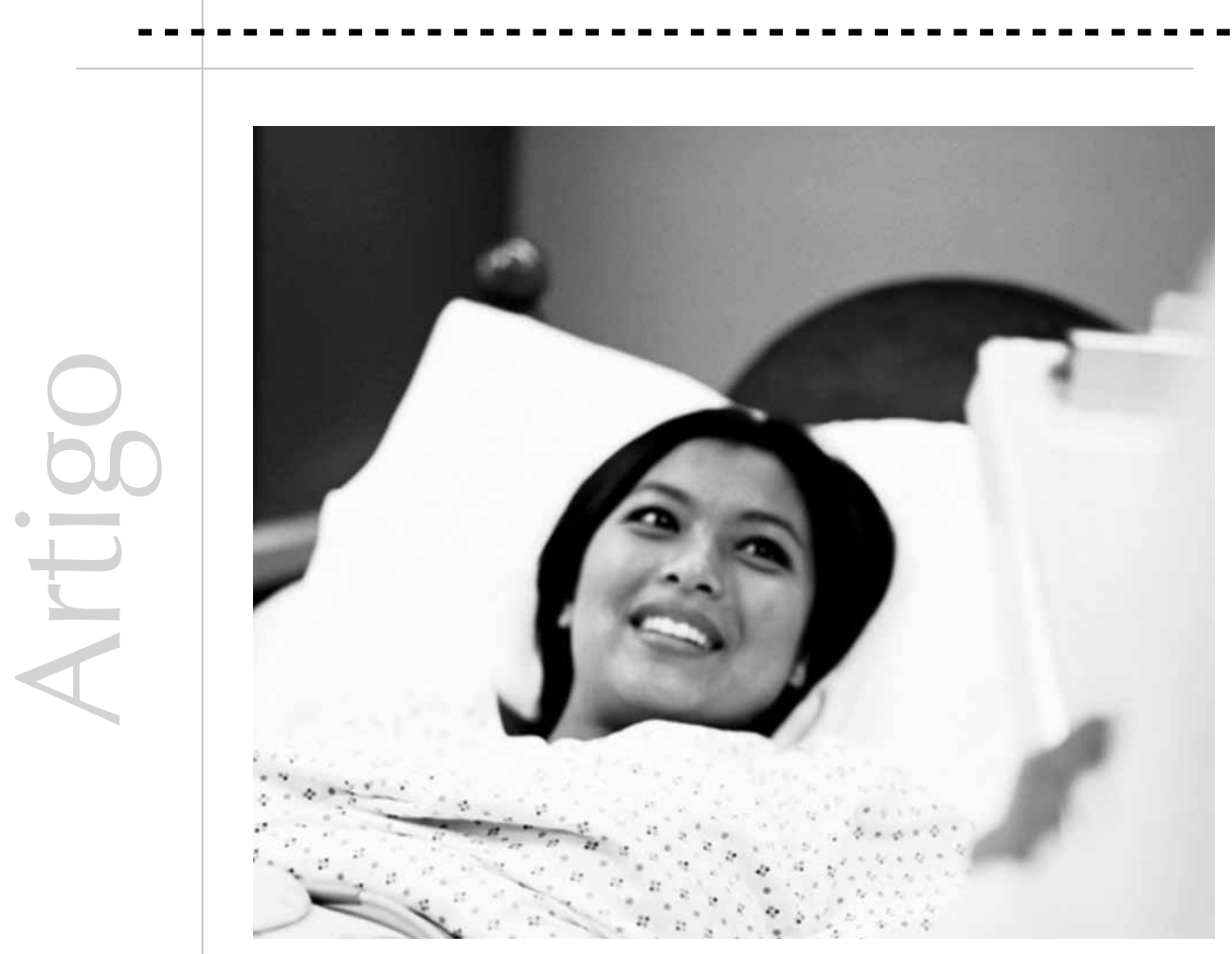


Resumo: Este artigo apresenta um ensaio sobre a prática do psicólogo como ouvidor hospitalar. Inicialmente, é avaliado o controle social no Sistema Público de Saúde (Conferências e Conselhos de Saúde, ouvidorias). O papel do ouvidor hospitalar no controle social no contexto da humanização do sistema de saúde é discutido a partir de um diálogo com autores da área da Saúde pública, das Ciências sociais e da Psicologia. Por humanização, entende-se a forma de assistência que valoriza a qualidade do cuidado do ponto de vista técnico e o reconhecimento dos direitos dos pacientes. Uma proposta de compreensão da ouvidoria hospitalar como um desafio para a Psicologia social da saúde é apresentada a partir de uma análise da produção teórica brasileira. Em seguida, discute-se uma experiência de trabalho de um psicólogo como ouvidor hospitalar. Ao fim, são apresentadas algumas sugestões a respeito do papel da Psicologia social no contexto da ouvidoria hospitalar como instrumento de controle social.

Palavras-chave: Ouvidoria hospitalar. Atuação do psicólogo. Humanização. Sistema de saúde.

\begin{abstract}
This paper presents an essay about the psychologist practice as health ombudsman. The social control (Health Councils, Health Conferences, Health Commissions) is initially evaluated. The role of the health ombudsman in social control in the context of humanization of the public health system is evaluated through a dialog with authors of the area of public health, social sciences and psychology. The humanization is a kind of assistance that gives importance to the technical quality association with recognition of the patient's rights. A proposal of the comprehension of Health Commissions as a challenge for social health psychology is presented taking into account an analysis of the Brazilian theoretical production. After that, an experience of the psychologist's work as health ombudsman is discussed in the end, and some suggestions about the role social psychology plays in the context of health ombudsman as social control instrument are presented. Keywords: Health ombudsman. Psychologist performance. Humanization. Health care system.
\end{abstract}

Resumen: Este artículo presenta un ensayo sobre la práctica del psicólogo como oyente de hospital. Inicialmente, es evaluado el control social en el Sistema Público de Salud (Conferencias y Consejos de Salud, servicio oyente). El papel del oyente de hospital en el control social en el contexto de la humanización del sistema de salud es discutido desde un diálogo con autores del área de la Salud pública, de las Ciencias sociales y de Psicología. Por humanización, se entiende la forma de asistencia que valora la calidad del cuidado del punto de vista técnico y el reconocimiento de los derechos de los pacientes. Una propuesta de comprensión del oyente de hospital como un desafío para la Psicología social de la salud es presentada desde un análisis de la producción teórica brasileña. Enseguida, se discute una experiencia de trabajo de un psicólogo como oyente de hospital. Al fin, son presentadas algunas sugerencias a respeto del papel de la Psicología social en el contexto de la oyente de hospital como instrumento de control social.

Palabras clave: Oyente de hospital. Actuación del psicólogo. Humanización. Sistema de salud.

Os estudos sobre controle social no campo da saúde têm se concentrado, acertadamente, na compreensão dos Conselhos como espaços de participação da sociedade civil na concepção e gestão de políticas públicas (Van Stralen et al., 2006). Criados pela Constituição Federal de 1988, os Conselhos Gestores de Políticas Públicas de caráter permanente e as conferências temáticas municipais, estaduais e nacionais propiciaram e sancionaram a participação de diversos atores sociais nos processos de tomada de decisão nos processos de formulação e gestão das políticas públicas. No caso do Campo da Saúde, a Lei no 8.142, de 28 de dezembro de 1990, criou um sistema de conselhos em cada esfera de governo, composto da seguinte forma: representantes dos usuários (50\% dos membros), trabalhadores (25\%) e gestores (25\%).

A questão da humanização e da qualidade dos serviços começou a aparecer a partir da XI Conferência Nacional de Saúde, intitulada Efetivando o SUS: Acesso, Qualidade e Humanização na Atenção à saúde com Controle Social, realizada no ano 2000. Alguns teóricos têm se dedicado a discutir o conceito de humanização, destacando-se os trabalhos de Ayres (2005) e Deslandes (2004, 2006). Em 1996, a X Conferência Nacional de Saúde emitiu um parecer favorável à criação das 
A partir do final da década de 80, os psicólogos começam a ter uma inserção significativa no campo da saúde pública

(Dimenstein, 1998). ouvidorias no SUS. A XII Conferência Nacional de Saúde, realizada em 2003, apresentou algumas contribuições para a construção da política nacional de ouvidoria do SUS: criar e implementar, nas três esferas de governo, um processo de escuta contínua e de interlocução entre os usuários do SUS, por intermédio de serviços telefônicos gratuitos, desenvolver ampla pesquisa para avaliar a satisfação dos usuários e dos profissionais do SUS e utilizar o instrumento da ouvidoria para fortalecer o controle social e a gestão participativa. Infelizmente, essas propostas não foram implementadas.

A partir do final da década de 80, os psicólogos começam a ter uma inserção significativa no campo da saúde pública (Dimenstein, 1998). A produção teórica, contudo, parece ainda não dialogar com as questões do SUS e o desafio da interdisciplinaridade (Bucher, 2003; Spink, 2007). A Psicologia da saúde, campo em construção em nosso país, poderia subsidiar as reflexões e pesquisas dos psicólogos que desejam efetivamente não apenas dialogar com o SUS mas também contribuir para sua consolidação como um serviço universal, de qualidade e com controle social qualificado. Spink (1992), em um trabalho pioneiro, afirmava, no início da década de 90, que havia uma ausência de reflexões sobre o processo saúde/doença, sobre a configuração dos serviços de saúde e das profissões que atuam nesse contexto, como também sobre as políticas públicas de saúde e sobre as suas implicações em relação aos usuários. A autora propôs um modelo que descrevia as linhas de investigação pertinentes à explicação do processo saúde/doença, destacando três dimensões: a compreensão da doença como fenômeno coletivo, a construção do saber leigo e a interface entre o saber oficial e a representação da doença que prevalece ao longo do tempo e em diferentes grupos.

Nos seus trabalhos posteriores, Spink (2001, 2003; Bonciani \& Spink 2003; Spink \&
Carvalheiro, 2002) desenvolveu uma série de pesquisas sobre a representação da AIDS, sobre os fundamentos teóricos da Psicologia da saúde, sobre a relação entre usuários e profissionais de saúde e a saúde como campo de pesquisa da Psicologia social, tornando-se uma referência obrigatória no campo da Psicologia da saúde. Uma questão apontada por ela na década de 90, que foi pouco investigada pela autora ou por outros pesquisadores da área, diz respeito à compreensão das implicações das políticas públicas da área para os usuários.

Recentemente, Spink e Matta (2007) discutiram os desafios da prática psicológica no contexto do SUS. Uma questão citada pelos autores foi a da humanização. De acordo com eles,

Os programas de humanização hospitalar que... resultaram na Política Nacional de Humanização apontam a necessidade de toda política e ação de saúde dever ter como eixo a humanização... Muitos psicólogos têm construído sua inserção nas unidades de saúde, contudo, muitas vezes, sem articulações com os princípios e diretrizes do SUS. Humanizar, no sentido proposto pelo Ministério da Saúde, é mais que reorganizar os espaços sanitários,é reorganizar os processos de trabalho, formar e qualificar trabalhadores, garantir os direitos e a cidadania dos usuários por meio do controle e da participação popular, é instituir práticas fundadas na integralidade. (p. 47)

O desafio de compreender o significado dos princípios da humanização propostos pelo SUS é também teórico, devendo ser respondido pela Psicologia da saúde produzido no contexto de nosso país. Alguns trabalhos já apresentam algumas contribuições significativas. Traverso-Yépez e Morais (2004) investigaram a forma como os usuários de saúde compreendem a situação em que desempenham o papel de pacientes, enfatizando os seguintes aspectos: 1) avaliação dos serviços recebidos; 2) consciência de seus direitos como pacientes 
e suas responsabilidades na melhoria dos serviços; 3) expectativas que possuíam em relação aos profissionais de saúde. Os resultados encontrados foram: inúmeras deficiências encontradas nos serviços de saúde e resignação e passividade por parte dos usuários em face do quadro encontrado. As autoras argumentam que a reconfiguração da relação profissionais/usuários é essencial para o processo de humanização das práticas da saúde. Uma questão deixada em aberto pelas pesquisadoras é a explicação dessa resignação e da passividade por parte dos usuários. Um motivo provável é a ausência de canais que permitam a expressão de suas queixas e que possam efetivamente oferecer respostas a elas. A ouvidoria seria esse canal.

Mota, Martins e Véras (2006) produziram outro trabalho que se centrou no papel do psicólogo no processo de humanização hospitalar, com a descrição dos princípios do SUS e a apresentação de algumas possibilidades para que o trabalho do psicólogo hospitalar possa efetivamente contribuir para o processo de humanização do hospital. Os autores, contudo, não reconhecem a ouvidoria como um espaço de atuação para o profissional de Psicologia no contexto do hospital.

O objetivo deste ensaio é contribuir, a partir da Psicologia da saúde, com uma compreensão do SUS como um espaço político em que o saber técnico permite uma forma específica do exercício da cidadania e no qual as ouvidorias possuem um grande potencial para a articulação do controle social e da humanização do serviço. Para isso, o trabalho se acha dividido em quatro seções: na primeira, discutem-se as formas de controle social no campo da saúde; na segunda, apresenta-se a especificidade da ouvidoria como forma de controle social no contexto da humanização do SUS, a ouvidoria hospitalar como questão para a Psicologia da saúde é o tema da terceira seção, e, finalmente, algumas reflexões sobre uma experiência de trabalho como ouvidor constituem a última seção. Nas considerações finais, apresentamos algumas sugestões para o aperfeiçoamento das ouvidorias e para novas investigações que possam lançar luz sobre o processo de humanização do SUS como um desafio para o trabalho dos psicólogos, tanto nos serviços de saúde como na Academia.

\section{As formas de controle social e o campo da saúde}

A reforma do setor de saúde no Brasil consignada na Constituição de 1988 tem seu eixo central na democratização dos serviços mediante o controle social do sistema. Vários mecanismos institucionais de participação da sociedade no controle do SUS foram criados ou reformulados. Vázquez et al. (2005) classificam essas instituições em dois tipos: coletivos e individuais. Os mecanismos institucionais coletivos seriam as Conferências e os Conselhos, enquanto as ouvidorias seriam os mecanismos de controle individual. Outra maneira de classificar esses mecanismos seria entendê-los a partir de variáveis dimensionais e funcionais. As Conferências e os Conselhos seriam macroestruturas de controle, caracterizadas pelos seguintes elementos: forma de participação coletiva e planejamento e gestão das políticas em nível abstrato. As ouvidorias seriam microestruturas de controle, caracterizadas por formas de participação individual e execução das políticas e nível local de ação.

Os estudos sobre o controle social estão concentrados nas macroestruturas, principalmente nos Conselhos (Costa, 2004; Gerschman, 2004; Guizardi \& Pinheiro, 2006; Guizardi et al., 2004; Liporoni, 2006; Macedo, 2005; Pedrosa, 1997; Sposati \& Lobo, 1992; Van Stralen et al., 2006; Vázquez et al., 2005). A macroestrutura mais antiga de controle social, porém, é a Conferência Nacional de Saúde, que foi criada pela Lei no 378, de 13 de janeiro de 1937, que determinou que as Conferências deveriam ocorrer de dois em dois anos. A I Conferência 
Nacional, realizada em 1941, não contou com participação social, o que se repetiria em todas as sete primeiras conferências.

Ocorrida em 1986, no contexto da reforma sanitária, a VIII Conferência Nacional de Saúde se tornou um marco no processo de democratização e controle social do sistema de saúde brasileiro. A etapa nacional foi precedida por Pré-Conferências estaduais para a discussão da temática e da escolha dos delegados. Os Estados realizaram suas pré-conferências, e em vários ocorreram pré-conferências municipais. Tal estratégia acabou gerando as Conferências Estaduais e Municipais de Saúde, que seriam incorporadas posteriormente na legislação do SUS (Krüger, 2005). A VIII Conferência não obedeceu aos padrões da Lei no 378, de 1937, e antecipou a configuração que seria dada às conferências nacionais pela Lei no 8.142, de 1990. Nessa Conferência, a saúde é definida com um conceito amplo; o direito à saúde é afirmado como uma conquista social que se efetiva na participação da população na organização, gestão e controle dos serviços e ações de saúde. O controle social é, portanto, definido como uma das formas de participação da população.

A IX Conferência Nacional aconteceu em agosto de 1992, depois de vários adiamentos realizados a partir de 1990, e o tema central foi: Saúde - Municipalização é o Caminho. Nessa conferência, de acordo com Guizardi et al. (2004), o projeto de participação desenhado na VIII Conferência foi restrito ao conceito de controle social, com ênfase na criação e no funcionamento dos Conselhos de Saúde. Essa tendência de centralizar o controle social na institucionalização dos Conselhos se acentua na $X$ Conferência, cujo tema foi SUS: Construindo um modelo de Atenção à Saúde para a Qualidade de Vida. Realizada em 1996, essa conferência também esboçou a necessidade de novas formas de participação.
A XI Conferência realizou-se em 2000, e teve como tema central o seguinte: Efetivando o SUS: Acesso, Qualidade e Humanização na Atenção à Saúde com Controle Social. Uma avaliação dos Conselhos e das Conferências de Saúde foi apresentada, assim, como diretriz para a sua organização. Inúmeras sugestões de espaços institucionais para o fortalecimento da participação social no controle das políticas e da gestão do SUS foram apresentadas, com destaque para câmaras técnicas, comissões temáticas, plenárias municipais, estadual e nacional de conselheiros, Conselhos Regionais e Distritais de saúde, fóruns de representação por segmentos, a criação de conselhos municipais e estaduais da cidadania, a criação de um conselho intersetorial e a instituição de ouvidorias, como já mencionamos.

A XII Conferência foi realizada por convocação extraordinária, em 2003, e teve como tema central Saúde: um Direito de Todos e um Dever do Estado - a Saúde que Temos, a Saúde que Queremos. A plenária da Conferência aprovou estratégias para a mobilização social, tais como o fortalecimento dos Conselhos de Saúde nas três esferas de governo e a implementação de uma política de ouvidorias do SUS com vários canais para que a população possa acessar para reclamar, apresentar sugestões e receber informações.

As pesquisas sobre os Conselhos de Saúde apontam uma dificuldade para a compreensão do que seja controle social (Gerschman, 2004), o pouco impacto que os Conselhos produzem na reestruturação dos serviços de saúde (Van Stralen et al., 2006), a dificuldade de os representantes dos usuários efetivamente participarem dos Conselhos, superando uma prática política formal de referendar as propostas do gestor (Guizardi \& Pinheiro, 2006), o desconhecimento da população acerca da existência dos Conselhos de Saúde e a incapacidade dos conselheiros de recolher e expressar os interesses da população que representam (Vázquez et al., 2005). Isso não significa que os Conselhos sejam inviáveis 
como espaços de construção do controle social. Somente a luta pelo controle efetivo e uma participação informada e representativa dos conselheiros poderá, de fato, transformar os Conselhos em territórios de constituição popular das políticas públicas de saúde.

\section{A especificidade da ouvidoria como forma de controle social no contexto da humanização do SUS}

\begin{abstract}
A XII Conferência Nacional de Saúde, realizada em 2003, propôs a criação de uma política nacional de ouvidorias do SUS para as três esferas de governo, com a aprovação dos respectivos Conselhos e com a garantia de recursos humanos e financeiros para a sua implementação nos Estados e Municípios. O objetivo dessa política deve ser ampliar os canais de participação da população no controle social do SUS.
\end{abstract}

O Glossário Temático Ouvidoria do SUS, publicado pelo Ministério da Saúde, em 2007, assim define Ouvidoria do SUS:

Canal de comunicação entre a população e o Sistema Único de Saúde (SUS) para o acolhimento de manifestações e busca de soluções e informações sobre os serviços de saúde pública... i) A Ouvidoria do SUS é um serviço de mediação entre o demandante e as áreas competentes pela resolução da demanda. ii) Constitui-se em um instrumento de participação social e de apoio à gestão democrática para melhorias do Sistema Único de Saúde. (Ministério da Saúde, 2007, p. 33)

As ouvidorias são microestruturas institucionais de controle social nas quais a ação individual é priorizada juntamente ao nível local, tendo na figura do ouvidor um mediador das demandas produzidas pelos usuários dos serviços.

No nível federal, o Decreto $\mathrm{n}$ o 4.726, de 9 de junho de 2003, criou a Ouvidoria Geral do SUS, tendo como um dos seus objetivos propor, coordenar e implementar a política nacional de saúde. Um dos elementos constituintes dessa política é a elaboração de diretrizes e de princípios de funcionamento do Sistema Nacional de Ouvidorias do SUS. Esse sistema deverá ter como parâmetros para a sua atuação alguns programas do Ministério da Saúde, tais como o QualiSUS, que estabelece a criação de ouvidorias em todos os hospitais e postos de saúde do programa, e a Política Nacional de Gestão Participativa (ParticipaSUS), que busca incentivar a participação popular na gestão do SUS.

As ouvidorias devem ser organizadas de modo a obedecerem aos princípios do SUS. Esses princípios seriam os seguintes:

a) universalidade: as ouvidorias devem estar estruturadas de modo que possam atender, de modo gratuito, as demandas de todo cidadão;

(b) integralidade: as demandas dos usuários devem receber atenção em todas as fases do processo, a saber: recebimento, encaminhamento, acompanhamento e resolutividade;

(c) eqüidade: as ouvidorias devem desenvolver estratégias de acolhimento que permitam o atendimento de todas as demandas recebidas;

d) descentralização: implantar as ouvidorias nas secretárias estaduais, municipais e nos serviços de saúde, com a definição das competências de cada uma;

e) regionalização: disponibilizar ouvidorias em cada região sanitária, seja em cidadespólo, seja em distritos sanitários;

f) hierarquização: as ouvidorias devem seguir a mesma lógica hierárquica do SUS, considerando as necessidades regionais;

g) participação da comunidade: as ouvidorias devem garantir às comunidades o recebimento 
de suas manifestações assim como possibilitar a sua participação na avaliação dos resultados obtidos a partir da leitura das demandas.

O Sistema Nacional de Ouvidorias trabalhará as demandas colocadas pelos usuários do SUS, a dimensão coletiva da sociedade na forma questões de saúde e a dimensão individual na forma de acolhimento do usuário de modo efetivo. Assim, a ouvidoria é um instrumento de promoção de cidadania na saúde e de acolhimento do usuário, atividade essencial no processo de humanização do SUS.

A XI Conferência Nacional de Saúde colocou o tema da humanização na atenção à saúde com controle social. Em 2000, o Programa Nacional de Humanização da Atenção Hospitalar (PNHAH) iniciou ações nos hospitais para a criação de comitês de humanização voltados para a melhoria na qualidade da atenção aos usuários. Posteriormente, o programa foi ampliado e passou a ser denominado de Política Nacional de Humanização da Atenção e da Gestão na Saúde (PNH).

A humanização, tanto na atenção hospitalar quanto na política de atenção à saúde, tem sido objeto de diversos estudos (Almeida, 2007; Ayres, 2004, 2005; Backes, Lunardi, \& Lunardi Filho, 2006; Benevides \& Passos, 2005a, 2005b; Boaretto, 2004; Campos, 2004; Campos, 2005; Casate \& Côrrea, 2005; Deslandes, 2004, 2006; Freitas, 2007; Gastado, 2005; Goldenstein, 2006; Gonçalves, 2007; Lucato, 2005; Medeiros, 2004; Minayo, 2004; Mota et al., 2006; Oliveira, Collet, \& Vieira, 2006; Puccini, \& Cecilio, 2004; Santos Filho, 2007; Silva, 2006; Teixeira, 2005; Traverso-Yépez \& Morais, 2004; Vaistman \& Andrade, 2006).

Deslandes (2004), analisando os textos Programa Nacional de Humanização da Assistência Hospitalar (Ministério da Saúde, 2001) e o Manual do Programa Nacional de Humanização da Assistência Hospitalar (Ministério da Saúde, 2000), descortina três eixos discursivos na Política Nacional de Humanização da Assistência Hospitalar: 1) humanização como oposição à violência; 2) humanização como capacidade de oferecer um atendimento de qualidade; 3) humanização como melhoria das condições de trabalho do cuidador; 4) humanização como ampliação do processo comunicacional. A violência se expressa de duas formas: física ou psicológica, como maus-tratos, e simbólica, pela não compreensão das demandas e expectativas. A violência simbólica somente será superada com a implementação de uma nova cultura de atendimento, caracterizada por uma relação de diálogo entre usuários, profissionais e gestores. Um atendimento de qualidade se sustenta em uma alta tecnologia e em uma "tecnologia leve", que diz respeito a questões de produção de vínculos, acolhimentos e autonomização (Mehry et al., 1997).

Uma questão central nesse processo é o desenvolvimento de uma "nova cultura de acolhimento" baseada nos valores da solidariedade e da alteridade, o que pressupõe que se conheça esse outro, suas expectativas, representações e práticas. Deslandes (2004) indaga a respeito dos mecanismos existentes que permitem a livre expressão dos usuários, afirmando que nada além dos espaços formais das ouvidorias se encontra disponível. Podemos questionar se o espaço da ouvidoria é necessariamente formal ou se ele pode se tornar um instrumento facilitador das verbalizações das demandas dos usuários, o que será discutido na próxima seção.

\section{A ouvidoria hospitalar como questão para a Psicologia da saúde}

Traverso-Yépez (2001), discutindo a interface Psicologia social e saúde, chama a atenção para a importância da dimensão dialógica da relação profissional de saúde-paciente. A ouvidoria hospitalar, do nosso ponto de vista, configura-se como uma questão que entrelaça 
o controle social com a temática da relação profissional-paciente.

A relação profissional saúde-paciente, quando ocorre com alguma dificuldade, gera o denominado "baixo comprometimento do paciente com seu tratamento". Os profissionais de saúde têm dificuldade de compreender esse comprometimento baixo (TraversoYépez \& Morais, 2004), mas as reclamações e críticas recebidas pelas ouvidorias e a baixa resolutividade revelam uma falência do modelo de assistência. Necessário se faz considerar a subjetividade dos usuários para melhor entendimento das condições necessárias para um comprometimento consciente, crítico e informado por parte dos pacientes em relação à assistência que lhes é prestada pelos serviços de saúde.

Essa dimensão subjetiva encontra-se apenas esboçada nos estudos sociológicos sobre ouvidoria hospitalar (Pereira, 2002). O estudo das ouvidorias apoiado nos conceitos de poder disciplinar e tecnologias de si, de Foucault (1990, 1996), destacam uma série de questões relevantes que a Psicologia social da saúde deveria investigar.

O trabalho pioneiro de Pereira (2002) indica que essas questões são o resultado de um bem conduzido estudo empírico. Para a socióloga gaúcha, as ouvidorias hospitalares promovem, concomitantemente, o envolvimento e o disciplinamento dos usuários. A autora afirma que há dois projetos de ouvidorias: no primeiro, enquanto micropolítica vinculada ao projeto neoliberal de alteração do sistema de saúde, a ouvidoria funciona como uma forma de gerenciamento, visando a otimizar a relação custo/benefício dos serviços hospitalares em uma lógica de mercado; no segundo, consoante com os princípios do SUS, a ouvidoria serve como um canal que assegura aos usuários o direito de terem suas vozes ouvidas pela instituição, promovendo uma micropolítica de controle social. A ouvidoria hospitalar possui um potencial de transformação da instituição hospitalar, carecendo para isso de maior transparência em sua gestão. A definição de um mandato para o ouvidor por um período determinado e a instituição de mecanismos mais democráticos de escolha (atualmente, os ouvidores são, na maioria, nomeados pelo diretor do hospital) ajudariam na potencialização da ouvidoria hospitalar como um instrumento de controle social. Pereira (2002) elaborou o conceito de ouvidoria eficaz, que teria as seguintes características: acolhida da reclamação dos usuários como uma consulta, incentivando-os a registrar suas demandas e a discutir sua implementação com os trabalhadores de saúde, envolvendoos no projeto. Em suas palavras,

Para que a ouvidoria possa atingir plenamente seus objetivos, o de ser um canal para ouvir a voz do cidadão, é necessário que tenha uma estrutura na qual a pessoa que é responsável tenha respaldo institucional, e não só da direção. Que a comunidade toda assuma a ouvidoria como um projeto institucional e a reclamação como uma questão eminentemente social e não apenas individual. Isso porque... as reclamações apontam relações sociais muitas vezes imperceptíveis aos olhos de quem as experiência. Agindo dessa forma, as ouvidorias hospitalares amplificariam a vOz dos usuários, propiciando uma melhoria da qualidade de atendimento nessas instituições. (p. 113)

\section{O psicólogo como ouvidor: reflexões sobre uma experiência}

No Piauí, a história da humanização no campo de saúde vincula-se à implementação do Programa Nacional de Humanização da Assistência Hospitalar (PNHA), em 2001. O programa selecionou, na sua 1a etapa, o Hospital Regional Justino Luz, localizado na cidade de Picos, como sede da experiênciapiloto. Na segunda etapa, iniciada em 2002, o programa foi implantado em outros sete 
hospitais, dentre os quais o Instituto de Doenças Tropicais Dr. Nathan Portela. O processo se consolidou institucionalmente com a criação de um Grupo de Trabalho de Humanização (GTH). Ainda em 2002, é criada a Comissão Estadual de Humanização da Assistência Hospitalar e realizada uma pesquisa sobre a satisfação de usuários e profissionais nos oitos hospitais integrantes do PNHA.

Em 2003, o Comitê Gestor do Programa Estadual de Humanização da Assistência Hospitalar é criado através de Portaria da Secretaria de Saúde do Estado do Piauí. Em 2005, a política Estadual de Humanização da Atenção e da Gestão da Saúde do Piauí foi aprovada. Entre as ações estratégicas definidas pela Política, há uma proposta de criação e/ou fortalecimento de ouvidorias nos estabelecimentos de saúde, com o objetivo de fortalecer o controle social.

O primeiro hospital do Piauí a implantar uma ouvidoria foi o Instituto de Doenças Tropicais Nathan Portela. Criado em 1973, o Hospital de Doenças Infecto-contagiosas (HDIC) começou a funcionar no início de 1974, com uma grande epidemia de meningite, que exigiu local especializado para atender o grande contingente de enfermos. Em 16 de fevereiro de 2000, o HDIC teve sua denominação alterada para Instituto de Doenças Tropicais Nathan Portella (IDTNP). Em 13 de setembro de 2004, era implantada a ouvidoria do IDTNP e instituído o Conselho de Ouvidoria, composto por 13 membros indicados por diversos órgãos de representação do Estado do Piauí. A primeira ouvidora foi a psicóloga Delfina Carvalho, que foi substituída posteriormente pela também psicóloga Vera Lúcia Macêdo Santana, que permaneceu no período de 2005-2006 na instituição. A direção do Hospital definiu, informalmente, que a coordenação da ouvidoria deveria ser ocupada por um profissional da Psicologia.
A Ouvidoria do IDTNP recebe a demanda dos usuários através dos seguintes meios: formulários elaborados pela Ouvidoria, endereço eletrônico, telefone, caixas de sugestões e comunicação verbal. O funcionamento ocorre da seguinte maneira: cada manifestação é examinada preliminarmente para decisão acerca de sua admissibilidade, verificando-se a pertinência da manifestação. Em alguns casos, os problemas são resolvidos de imediato; em outras ocorrências, há comunicação para os setores competentes para que os mesmos tomem conhecimento, adotem as providências necessárias e esclareçam as questões suscitadas. As informações fornecidas pelos setores e os procedimentos adotados ficam disponíveis para os usuários na sala da Ouvidoria, sendo posteriormente arquivadas.

O trabalho do ouvidor apresenta alguns desafios por ser, ao mesmo tempo, um canal de comunicação entre usuários, profissionais e gestores e também pelo fato de possuir características de mediação. No trabalho realizado na Ouvidoria do IDTNP, ocorre a seguinte configuração das manifestações: predominantemente escrita, apresenta um número significativo de elogios e tem como principal reclamação o mau atendimento, além de queixas sobre desconforto ambiental, serviço de limpeza e serviço de nutrição.

Haveria uma contradição entre o trabalho do psicólogo no hospital e o trabalho de ouvidor? Certamente as tarefas são distintas, mas, se consideramos que a Psicologia, no Hospital, ao contrário do que afirmam Mota, Martins e Véras (2006), não consiste apenas em lidar com os sentimentos dos pacientes, é possível conceber algumas convergências entre as duas funções. O psicólogo não deve se restringir a trabalhar com os usuários dos serviços de saúde, mas deve também desenvolver atividades com a equipe de profissionais e demais funcionários desses serviços. $\mathrm{O}$ psicólogo no contexto da saúde, assim como 
A Psicologia

hospitalar é uma peculiaridade brasileira (Castro \& Bornholdt, 2004), sendo marcada pela hegemonia de um conceito subjetivista e individualista do ser humano. o ouvidor, deve também trabalhar com informações. Rozemberg, Silva e VasconcelosSilva (2002), a partir de entrevistas com profissionais de um hospital do Rio de Janeiro, avaliaram um conjunto de pressupostos, estratégias, preocupações e racionalidades dos profissionais que produziram mensagens impressas sobre doenças infecciosas. A maioria das produções revelou possuir uma lógica linear de comunicação, na qual uma mensagem necessariamente produz um único e só efeito. A pesquisa revelou que os impressos produzidos apresentavam simplificações e generalizações sobre as dúvidas e os questionamentos mais comuns dos pacientes, em função da inexistência de pesquisas prévias com esses usuários. A interação com a clientela aparece como exceção, ocorrendo em apenas duas das produções analisadas. Os autores concluem que existe a ausência de uma política de comunicação regular e saudável dentro das instituições de saúde. A criação dessa política deve, necessariamente, passar por uma ampla discussão envolvendo os usuários dos serviços de saúde. As ouvidorias poderiam desempenhar um papel pró-ativo no controle social, e os psicólogos poderiam ir além dos sentimentos para lidarem com o ser humano na sua integralidade. O trabalho de ouvidoria no IDTNP envolveu a produção de um folder explicativo sobre as funções da Ouvidoria e como utilizá-la, como também a participação da ouvidora, em parceria com o serviço social, na elaboração de um Manual dos Direitos e Deveres do Paciente.

A experiência de trabalho em uma ouvidoria pode ser de grande importância para produzir um distanciamento crítico em relação ao papel tradicional do psicólogo no contexto da saúde e nos processos de humanização. Relacionar humanização e controle social é algo impositivo no trabalho da ouvidoria, mas quase sempre estão desvinculadas no trabalho do psicólogo no contexto hospitalar (Almeida, 2000; Fossi \& Guareschi, 2004; Marcon, Luna, \& Lisboa, 2004; Tonetto \& Gomes,
2007). Tal quadro talvez se relacione com a formação da área de Psicologia hospitalar em nosso país, em contraste com uma Psicologia da saúde, área mais abrangente e diversificada e que se estruturou em outros países. A Psicologia hospitalar é uma peculiaridade brasileira (Castro \& Bornholdt, 2004), sendo marcada pela hegemonia de um conceito subjetivista e individualista do ser humano.

Apesar disso, é possível perceber a contribuição de outros saberes para o trabalho do psicólogo no contexto hospitalar. O trabalho de Maia (2006), que utiliza a análise institucional, mostra como a demanda institucional chega ao psicólogo hospitalar mediada pela interconsulta médica, que busca adaptar a prática do psicólogo a uma lógica institucional de caráter normatizador e disciplinador. Uma estratégia diferente seria pesquisar como os psicólogos avaliam o papel da ouvidoria, comparando o que pensam os psicólogos hospitalares com as opiniões de psicólogos que exercem ou exerceram a função de ouvidores.

\section{Considerações finais}

O processo de humanização do sistema de saúde passa necessariamente, como bem colocou o tema da X Conferência Nacional de Saúde, pelo controle social. As macroestruturas de controle social, Conferências e Conselhos, não permitem o enfrentamento dos mecanismos de normatização e de exclusão da cidadania que ocorrem no nível das micropolíticas de saúde, engendradas no interior das várias instituições do SUS. Necessário se faz construir microestruturas de controle social, e as ouvidorias possuem um grande potencial para ocuparem essa função. O desafio de compreender essa dimensão das microestruturas no contexto da saúde permanece como um caminho inexplorado pela Psicologia social da saúde no Brasil, com exceção de alguns trabalhos, com destaque para os produzidos por Traverso-Yépez $(2001,2004)$. As ouvidorias, no contexto das 
instituições de saúde, entretanto, ainda não receberam nenhuma atenção dos estudiosos da Psicologia social.

No contexto hospitalar, as ouvidorias apresentam um duplo desafio para a Psicologia social da saúde: compreender a micropolítica da instituição hospitalar, que tende a desenvolver uma prática disciplinadora incompatível com o exercício da cidadania, e a instituição da ouvidoria como instância em que uma micropolítica de controle social pode ser desenvolvida, de um lado, e, por outro, oferecer subsídios teóricos para a capacitação de ouvidores, compreendendo a dimensão política do trabalho na saúde, em contraposição a uma Psicologia da saúde centrada nos "sentimentos".

Denis Barros de Carvalho*

Psicólogo, Doutor em Psicologia social pela Universidade Federal do Rio Grande do Norte, professor da Universidade Federal do Piauí.

\section{Janaína Macêdo Santana}

Engenheira civil, professora substituta da Universidade Estadual do Piauí.

Vera Macêdo de Santana

Psicóloga e ex-ouvidora do Instituto de Doenças Tropicais Natan Portella.

*Endereço para envio de correspondência:

Rua Trevos, no 1125, Morada do Sol. Cep: 64056-210 - Teresina-PI.

E-mail: denisclio@uol.com.br.

Recebido 08/12/2007; Reformulado 11/10/2008; Aprovado 13/10/2008.

Referências
Almeida, D. V. (2007). O ensino da humanização nos currículos de graduação em enfermagem. Dissertação de Mestrado, Escola de Enfermagem, Universidade de São Paulo, São Paulo.

Almeida, E. (2000). O psicólogo no hospital geral. Psicologia: Ciência e Profissão, 20(3), 24-27.

Ayres, J. R. (2004). Humanização da assistência hospitalar e o cuidado como categoria reconstrutiva. Ciência \& Saúde Coletiva, 9(1), 15-17.

Ayres, J. R. (2005). Hermenêutica e humanização das práticas de saúde. Ciência \& Saúde Coletiva, 10(3), 549-560.

Backes, D., Lunardi, V., \& Lunardi Filho, W. (2006). A humanização hospitalar como expressão da ética. Revista Latino-Americana de Enfermagem, 14(1), 132-135.

Benevides, R., \& Passos, E. (2005a). A humanização como dimensão pública das políticas de saúde. Ciência \& Saúde Coletiva, 10(3), 561-571.

Benevides, R., \& Passos, E. (2005b). Humanização na saúde: um novo modismo? Interface, 9(17), 389-394.

Boaretto, C. (2004). Humanização da assistência hospitalar: o dia a dia da prática dos serviços. Ciência \& Saúde Coletiva, 9(1), 20-22.

Bonciani, R. D., \& Spink, M. J. (2003). Morte por AIDS ou morte materna: a classificação da mortalidade como prática social. Cadernos de Saúde Pública, 19(2), 645-652.

Bucher, J. S. (2003). Psicologia da saúde no contexto da saúde pública: uma complexidade crescente. In O. Yamamoto \& V. Gouveia (Orgs.), Construindo a psicologia brasileira: desafios da ciência e prática psicológica (pp. 213-239). São Paulo: Casa do Psicólogo.

Campos, G. W. S. (2005). Humanização na saúde: um projeto em defesa da vida? Interface: Comunicação, Saúde, Educação, 9(17), 398-400.

Campos, R. (2004). Mudando os processos de subjetivação em prol da humanização da assistência. Ciência \& Saúde Coletiva, 9(1), 23-25.

Casate, J., \& Corrêa, A. K. (2005). Humanização do atendimento em saúde: conhecimento veiculado na literatura brasileira de enfermagem. Revista Latino-Americana de Enfermagem, 13(1), 105-111.

Castro, E., \& Bornholdt, E. (2004). Psicologia da saúde x psicologia hospitalar: definições e possibilidades de inserção profissional. Psicologia: Ciência e Profissão, 24(3), 48-57.

Costa, A. M. (2004). Conselhos gestores de políticas públicas: entre a ampliação dos direitos sociais e a legitimação das decisões governamentais. Dissertação de Mestrado, Universidade Federal Fluminense, Niterói, RJ.

Deslandes, S. (2004). Análise do discurso oficial sobre a humanização da assistência hospitalar. Ciência \& Saúde Coletiva, 9(1), 7-14.

Deslandes, S. (2006). Humanização dos cuidados em saúde: conceitos, dilemas e práticas. Rio de Janeiro: FIOCRUZ.

Dimenstein, M. (1998). O psicólogo no contexto do Sistema Único de Saúde (SUS): perfil profissional e perspectivas de atuação nas Unidades Básicas de Saúde. Tese de Doutorado, Universidade Federal do Rio de Janeiro, Rio de Janeiro.

Fossi, L., \& Guareschi, N. (2004). A Psicologia hospitalar e as equipes multidisciplinares. Revista da Sociedade Brasileira de Psicologia Hospitalar, 7(1), 29-43.

Foucault, M. (1990). Tecnologias del Yo y otros textos afines. Barcelona: Siglo Ventiuno.

Foucault, M. (1996). Vigiar e punir. Petrópolis, RJ: Vozes.

Freitas, B. (2007). O assistente social na assistência hospitalar e o desafio da humanização: reflexões sobre a dimensão intersubjetiva da prática profissional. Rio de Janeiro: PUC.

Gastado, D. (2005). Humanização como processo conflitivo, coletivo 
e contextual. Interface, 9(17), 395-397.

Gerschman, S. (2004). Conselhos Municipais de Saúde: atuação e representação das comunidades populares. Cadernos de Saúde Pública, 20(6), 1670-1681.

Goldenstein, E. (2006). Um estudo preliminar sobre humanização hospitalar: dando vOZ a médicos de UTI pediátrica sobre suas vivências em um hospital humanizado. São Paulo: PUC.

Gonçalves, M. (2007). Políticas de humanização e o direito à saúde no Rio Grande do Sul. Dissertação de Mestrado, Faculdade de Filosofia e Ciências Humanas, Pontifícia Universidade Católica do Rio Grande do Sul, Porto Alegre.

Guizardi, F. L., \& Pinheiro, R. (2006). Dilemas culturais, sociais e políticos da participação dos movimentos sociais nos Conselhos de Saúde. Ciência \& Saúde Coletiva, 17(3), 797-805.

Guizardi, F. L., Pinheiro, R., Mattos, R. A., Santana, A. D., Matta, G., \& Gomes, M. C. P. A. (2004). Participação da comunidade em espaços públicos de saúde: Uma análise das conferências nacionais de saúde. PHYSIS: Revista de Saúde Coletiva, 14(1), 15-39.

Krüger, T. R. (2005). Os fundamentos ideo-políticos das Conferências Nacionais de Saúde. Tese de Doutorado, Universidade Federal de Pernambuco, Recife: UFPE.

Liporoni, A. A. R. C. (2006). O Conselho Municipal de Saúde de Franca: estudo sobre a participação e o controle social. Dissertação de Mestrado, Faculdade de Medicina, Universidade de São Paulo, Ribeirão Preto, SP.

Lucato, M. C. (2005). A humanização das relações assistenciais no Código de Ética Odontológica - Resolução CFO $n$. 42/2003. Dissertação de Mestrado, Faculdade de Odontologia, Universidade de São Paulo, São Paulo.

Macedo, L. C. (2005). Participação e controle social na área de saúde: uma revisão bibliográfica. Dissertação de Mestrado, Escola de Enfermagem, Universidade de São Paulo, Ribeirão Preto, SP.

Maia, S. M. (2006). A interconsulta psicológica no hospital geral: uma demanda institucional. Dissertação de Mestrado, Faculdade de Filosofia e Ciências Humanas, Universidade Federal de Belo Horizonte, Belo Horizonte.

Marcon, C., Luna, I., \& Lisboa, M. (2004). O psicólogo nas instituições hospitalares: características e desafios. Psicologia: Ciência \& Profissão, 24(1), 28-35.

Medeiros, L. (2004). Humanização hospitalar, ambiente físico e relações assistenciais: a percepção de arquitetos especialistas. Dissertação de Mestrado, Universidade Federal do Rio Grande do Norte, Natal.

Mehry, E. E., Chakkour, M., Stéfano, E., Santos, C. M., Rodrigues, R. A., \& Oliveira, P. C. P. (1997). Em busca de ferramentas analisadoras das tecnologias em saúde: a informação e o dia a dia de um serviço, interrogando e gerindo trabalho em saúde. In E. E. Mehry \& R. Onocko (Orgs.), Agir em saúde: um desafio para a saúde pública (pp. 113-150). São Paulo: Hucitec.

Minayo, M. (2004). Dilemas do setor saúde diante de suas propostas humanistas. Ciência \& Saúde Coletiva, 9(1), 17-20.

Ministério da Saúde. (2000). Manual do Programa Nacional de Humanização da Assistência Hospitalar. Brasília, DF: Autor.

Ministério da Saúde. (2001). Programa Nacional de Humanização da Assistência Hospitalar. Brasília, DF: Autor.

Ministério da Saúde. (2007). Glossário temático: ouvidoria do SUS. Brasília, DF: Autor.

Mota, R., Martins, C., \& Véras, R. (2006). Papel dos profissionais de saúde na política de humanização hospitalar. Psicologia em Estudo, 11(2), 323-330.

Oliveira, B., Collet, N., \& Vieira, C. (2006). A humanização na assistência à saúde. Revista Latino-Americana de Enfermagem, 14(2), 277-284.

Pedrosa, J. I. (1997). A construção do significado de controle social com conselheiros de saúde no Piauí, Brasil. Cadernos de Saúde Pública, 13(4), 741-748.

Pereira, L. H. (2002). A voz do usuário no sistema hospitalar: ouvidorias. Sociologias, 4(1), 82-121.

Puccini, P., \& Cecílio, L. C. (2004). A humanização dos serviços e o direito à saúde. Cadernos de Saúde Pública, 20(5), 1342-1353.

Rozemberg, B., Silva, A., \& Vasconcellos-Silva, P. (2002). Impressos hospitalares e a dinâmica de construção de seus sentidos: o ponto de vista dos profissionais de saúde. Cadernos de Saúde Pública, 18(6), 1685-1694.

Santos Filho, S. (2007). Perspectivas da avaliação na Política Nacional de Humanização em Saúde: aspectos conceituais e metodológicos. Ciência \& Saúde Coletiva, 12(4), 999-1010.

Silva, G. S. N. (2006). A construção do "ser médico" e a morte: significados e implicações para a humanização do cuidado. Tese de Doutorado, Faculdade de Medicina, Universidade de São Paulo, São Paulo.

Spink, M. J. (1992). Psicologia da saúde: a estruturação de um novo campo de saber. In. F. Campos (Org.), Psicologia e saúde: repensando práticas (pp. 11-23). São Paulo: Hucitec.

Spink, M. J. (2001). A construção da AIDS - notícia. Cadernos de Saúde Pública, 17(4), 851-862.

Spink, M. J. (2003). Psicologia social e saúde: práticas, saberes e sentidos. Petrópolis, RJ: Vozes.

Spink, M. J. (2007). (Org.). A psicologia em diálogo com o SUS: prática profissional e produção acadêmica. São Paulo: Casa do Psicólogo.

Spink, M. J., \& Carvalheiro, J. R. (2002). Os múltiplos sentidos das vacinas para a Aids. Psicologia USP, 13(1), 79-106.

Spink, M. J., \& Matta, G. (2007). A prática profissional Psi na saúde pública: configurações históricas e desafios contemporâneos. In M. J. Spink (Org.), A Psicologia em diálogo com o SUS: prática profissional e produção acadêmica (pp. 25-51). São Paulo: Casa do Psicólogo.

Sposati, A., \& Lobo, E. (1992). Controle social e políticas de saúde. Cadernos de Saúde Pública, 20(6), 1670-1681.

Teixeira, R. (2005). Humanização e atenção primária à saúde. Ciência \& Saúde Coletiva, 10(3), 585-597.

Tonetto, A., \& Gomes, W. (2007). A prática do psicólogo hospitalar em equipe multidisciplinar. Estudos de Psicologia (Campinas), 24(1), 89-98.

Traverso-Yépez, M. (2001). A interface psicologia social e saúde: perspectivas e desafios. Psicologia em Estudo, 6(2), 49-56.

Traverso-Yépez, M., \& Morais, N. (2004). Reivindicando a subjetividade dos usuários da Rede Básica de Saúde: para uma humanização do atendimento. Cadernos de Saúde Pública, 20(1), 80-98

Vaitsman, J., \& Andrade, G. (2006). Satisfação e responsividade: formas de medir a qualidade e a humanização da assistência à saúde. Ciência \& Saúde Coletiva, 10(3), 599-613.

Van Stralen, C. J., Lima, A. M. D., Fonseca Sobrinho, D., Saraiva, L. E. S., Van Stralen, T. B. S., \& Belisário, S. A. (2006). Conselhos de Saúde: efetividade do controle social em Municípios de Goiás e Mato Grosso do Sul. Ciência \& Saúde Coletiva, 11(3), 621-632.

Vázquez, M. L., Silva, M. R. F., Gonzalez, E. S. C., Diniz, A. S., Pereira, A. P. C., Veras, I. C. L. et al. (2005). Nível de informação da população e utilização dos mecanismos institucionais de participação social em saúde em dois Municípios do Nordeste do Brasil. Ciência \& Saúde Coletiva, 10(Supl.), 141-155. 